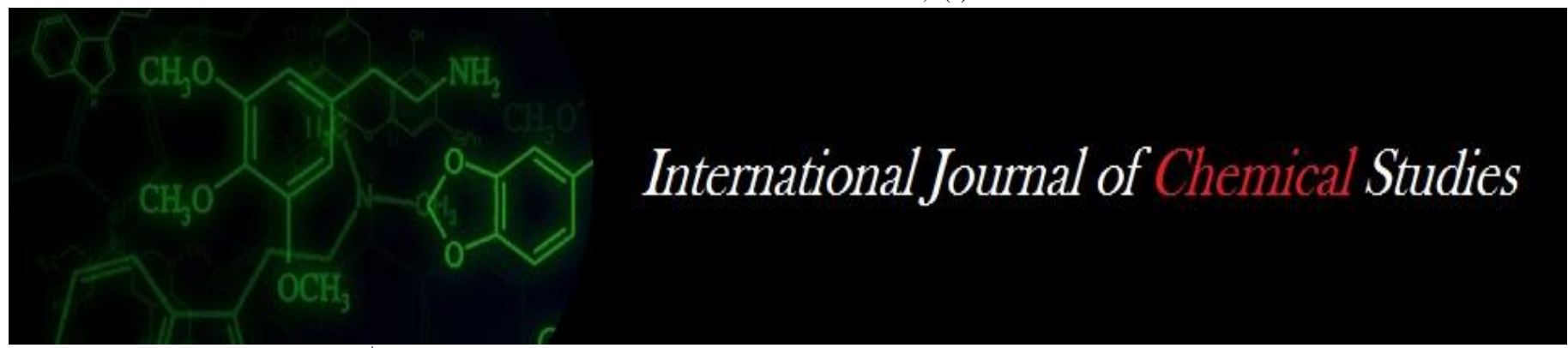

P-ISSN: 2349-8528

E-ISSN: 2321-4902

IJCS 2020: 8(1): 139-142

(C) 2020 IJCS

Received: 28-11-2019

Accepted: 30-12-2019

Ritu Ranjan Taye Junior Scientist, Regional Agricultural Research Station, Karimganj, Assam, India

\section{Shimantini Borkataki}

Assistant Professor, Department of Entomology, Assam Agricultural University, Jorhat, Assam, India
Corresponding Author: Ritu Ranjan Taye Junior Scientist, Regional Agricultural Research Station, Karimganj, Assam, India

\section{Role of secondary metabolites in plant defense against insect herbivores}

\author{
Ritu Ranjan Taye and Shimantini Borkataki
}

\begin{abstract}
In all natural habitats, plants are surrounded by an enormous number of potential enemies (biotic) and various kinds of abiotic environmental stress, greatly responsible for heavy reduction in crop productivity. To counter the herbivore attack, plants produce defensive compounds that appear to have no direct function in growth and development. These substances are known as secondary metabolites. Secondary metabolites, including terpenes, phenolics and nitrogen $(\mathrm{N})$ containing compounds, defend plants against a variety of insect herbivores. These compounds are either produced constitutively or in response to plant damage, and affect feeding, growth, and survival of herbivores. Many compounds act directly on the herbivore, whereas others act indirectly via the attraction of organisms from other trophic levels that, in turn, protect the plant. The role of secondary metabolites in defense may involve deterrent and anti-feedant activity, toxicity or acting as precursors to physical defense systems. By virtue of their biological activities against insect herbivores, many of these substances are employed commercially as insecticides, while others find uses as fragrances, flavorings, medicinal drugs, and industrial materials.
\end{abstract}

Keywords: Secondary metabolites, terpenes, phenolics and nitrogen containing compounds, deterrent, anti-feedant

\section{Introduction}

In natural systems, plants face a plethora of antagonists and thus posses a myriad of defense and have evolved multiple defense mechanisms by which they are able to cope with various kinds of biotic and abiotic stress ${ }^{[1]}$. There are various other modes of defense include the construction of polymeric barriers to pathogen penetration and the synthesis of enzymes that degrade pathogen cell wall ${ }^{[2]}$. In addition, plants employ specific recognition and signaling systems enabling the rapid detection of pathogen invasion and initiation of vigorous defensive responses ${ }^{[3]}$. Once infected, some plants also develop immunity to subsequent microbial attacks ${ }^{[4]}$. Plants produce a high diversity of natural products or secondary metabolites with a prominent function in the protection against predators and microbial pathogens on the basis of their toxic nature and repellence to herbivores and microbes and some of which also involved in defense against abiotic stress (e.g. UV-B exposure) and also important for the communication of the plants with other organisms ${ }^{[5]}$, and are insignificant for growth and developmental processes ${ }^{[6]}$. There are three major groups of secondary metabolites viz terpenes, phenolics and $\mathrm{N}$ and $\mathrm{S}$ containing compounds. Terpenes composed of 5-C isopentanoid units, are toxins and feeding deterrents to many herbivores. Phenolics synthesized primarily from products of the shikimic acid pathway, have several important defensive role in the plants. Members of the third major group i.e. $\mathrm{N}$ and $\mathrm{S}$ containing compounds are synthesized principally from common amino acids ${ }^{[7]}$. It is believed that most of the 100,000 known secondary metabolites are to be involved in plant chemical defense systems, which are formed throughout the millions of years during which plants have coexisted with their attackers. Although higher concentrations of secondary metabolites might result in a more resistant plant, the production of secondary metabolites is thought to be costly and reduces plant growth and reproduction ${ }^{[8]}$.

\section{Secondary metabolites}

Plants produce a large and diverse array of organic compounds that appear to have no direct functions in growth and development i.e. they have no generally recognized roles in the process of photosynthesis, respiration, solute transport, translocation, nutrient assimilation and differentiation ${ }^{[9]}$. They have a very restricted distribution than primary metabolites in the 
whole plant kingdom i.e. they are often found only in one plant species or a taxonomically related group of species. Their production is thought to be costly and reduces plant growth and reproduction ${ }^{[8]}$. Therefore, defense metabolites can be divided in to constitutive substances, also called prohibitins or phytoanticipins and induced metabolites formed in response to an infection involving de novo enzyme synthesis, known as phytoalexins ${ }^{[10]}$. Phytoanticipins are high energy and carbon consuming and exhibit fitness cost under natural conditions [11], but recognized as the first line of chemical defense that potential pathogens have to overcome. In contrast, phytoalexin production may take two or three days, as by definition first the enzyme system needs to be synthesized.

\section{Principal groups}

Plant secondary metabolites can be divided into three chemically distinct groups viz: Terpenes, Phenolics, N containing compounds.

\section{(i) Terpenes}

Terpenes constitute the largest class of secondary metabolites and are united by their common biosynthetic origin from acetyl-coA or glycolytic intermediates. A vast majority of the different terpenes structures produced by plants as secondary metabolites that are presumed to be involved in defense as toxins and feeding deterrents to a large number of plant feeding insects and mammals ${ }^{[12]}$.

(a) Monoterpenes $\left(\mathbf{C}_{10}\right)$ : Many derivatives are important agents of insect toxicity. For example, the pyrethroids (monoterpenes esters) occur in the leaves and flowers of Chrysanthemum species show strong insecticidal responses (neurotoxin) to insects like beetles, wasps, moths, bees, etc. and a popular ingredient in commercial insecticides because of low persistence in the environment and low mammalian toxicity ${ }^{[13]}$.

In Gymnosperms (conifers) like Pine and Fir, monoterpenes accumulate in resin ducts found in the needles, twings and trunks mainly as $\alpha$-pinene, $\beta$-pinene, limonene and myrecene, all are toxic to numerous insects including bark beetles, serious pest of conifer species throughout the world ${ }^{[13]}$.

(b) Sesquiterpenes ( $\left.\mathbf{C}_{15}\right)$ : A number of sesquiterpenes have been till now reported for their role in plant defense such as costunolides are antiherbivore agents of family composite characterized by a five membered lactone ring (a cyclic ester) and have strong feeding repellence to many herbivorous insects and mammals ${ }^{[14]}$.

$\mathrm{ABA}$ is also a sesquiterpene plays primarily regulatory roles in the initiation and maintenance of seed and bud dormancy and plants response to water stress by modifying the membrane properties and act as a transcriptional activator ${ }^{[15]}$. In addition, it increases the cytosolic calcium concentration and causes alkalinisation of the cytosol ${ }^{[16]}$.

(c) Diterpenes $\left(\mathbf{C}_{20}\right)$ : Abietic acid is a diterpene found in pines and leguminous trees. It is present in or along with resins in resin canals of the tree trunk. When these canals are pierced by feeding insects, the outflow of resin may physically block feeding and serve as a chemical deterrent to continued predation. Another compound phorbol (diterpene ester), found in plants of Euphorbiaceae and work as skin irritants and internal toxins to mammals. Moreover, phytol a highly hydrophobic 20-C alcohol found in chlorophyll as a side chain help to anchor certain molecules in membranes and therefore increase the efficiency of chlorophyll during the photosynthesis ${ }^{[17]}$, a strategy for maximum $\mathrm{CO}_{2}$ fixation and biomass production ${ }^{[18]}$.

(d) Triterpenes $\left(\mathbf{C}_{30}\right)$ : Several steroid alcohols (sterols) are important component of plant cell membranes, especially in the plasma membrane as regulatory channels and maintain permeability to small molecules by decreasing the motion of the fatty acid chains. The milkweeds produce several better tasting glucosides (sterols) that protect them against herbivory by most insects and even cattle ${ }^{[19]}$. Phytoecdysones have some defensive role against insects by disrupting moulting and other developmental and physiological processes with lethal consequences. Another triterpene, limnoid, a group of bitter substances in citrus fruits and act as antiherbivore compounds in members of family Rutaceae and some other families also. For example, Azadirechtin, a complex limnoid from Azadirachta indica, acts as a feeding deterrent to some insects and exerts various toxic effects ${ }^{[20]}$.

(e) Polyterpenes (C5) $)_{n}$ : Several high molecular weight polyterpenes occur in plants. Larger terpenes include the tetraterpenes and the polyterpenes. The principal tetraterpenes are carotenoids family of pigments. Other one is rubber, a polymer containing 1500-15000 isopentenyl units, in which nearly all the $\mathrm{C}-\mathrm{C}$ double bonds have a cis $(\mathrm{Z})$ configuration while in gutta rubber has its double bond in trans (E) configuration. Rubber found in long vessels called laticifers, provide protection as a mechanism for wound healing and as a defense against herbivores ${ }^{[21]}$.

\section{(ii) Phenolic compounds}

Plants produce a large variety of secondary products that contain a phenol group, a hydroxyl functional group on an aromatic ring called Phenol, a chemically heterogeneous group also. They could be an important part of the plants defense system against pests and diseases including root parasitic nematodes ${ }^{[2]}$.

(a) Coumarin: They are simple phenolic compounds, widespread in vascular plants and appear to function in different capacities in various plant defense mechanisms against insect herbivores and fungi. They derived from the shikimic acid pathway ${ }^{[23]}$, common in bacteria, fungi and plants but absent in animals. Also, they are a highly active group of molecules with a wide range of anti-microbial activity against both fungi and bacteria. It is believed that these cyclic compounds behave as natural pesticidal defense compounds for plants and they represent a starting point for the exploration of new derivatives possessing a range of improved antifungal activity.

Halogenated coumarin derivatives work very effectively in vitro to inhibit fungal growth. For example, 7-hydroxylated simple coumarins may play a defensive role against parasitism of Orobanche cernua, by preventing successful germination, penetration and connection to the host vascular system ${ }^{[24]}$.

(b) Furano-coumarins: Also a type of coumarin with special interest of phyto-toxicity, abundant in members of the family Umbelliferae including celery parsnip and parsley. Normally, these compounds are not toxic, until they are activated by light (UV-A), causes some furano-coumarins to become activated to a high energy electronic state, which can insert 
themselves into the double helix of DNA and bind to the pyramidine bases and thus blocking transcription and repair and eventually leading to cell death ${ }^{[25]}$. Psoralin, a basic linear furacoumarin, known for its use in the treatment of fungal defense and found very rarely in $\mathrm{SO}_{2}$ treated plants.

(c) Ligin: It is a highly branched polymer of phenylpropanoid groups, formed from three different alcohols viz., coniferyl, coumaryl and sinapyl which oxidized to free radicals (ROS) by a ubiquitous plant enzyme-peroxidase, reacts simultaneously and randomly to form lignin. Its physical toughness deters feeding by herbivorous animals and its chemical durability makes it relatively indigestible to herbivores and insects pathogens. Lignifications block the growth of pathogens and are a frequent response to infection or wounding ${ }^{[26]}$.

(d) Flavonoids: One of the largest classes of plant phenolic, perform very different functions in plant system including pigmentation and defense Two other major groups of flavonoids found in flowers are flavones and flavonols function to protect cells from UV-B radiation because they accumulate in epidermal layers of leaves and stems and absorb light strongly in the UV-B region while letting visible (PAR) wavelengths throughout uninterrupted. In addition, exposure of plants to increased UV-B light has been demonstrated to increase the synthesis of flavones and flavonols suggesting that flavonoids may offer a measure of protection by screening out harmful UV-B radiation ${ }^{[27]}$.

(e) Tanins: It included under the second category of plant phenolic polymers with defensive properties. Tannins are general toxins that significantly reduce the growth and survivorship of many herbivores and also act as feeding repellents to a great diversity of animals. In mammalian herbivores, they cause a sharp, astringent sensation in the mouth as a result of their binding of salivary proteins. Mammals such as cattle, deer and apes, characteristically avoid plant with high tannin contents ${ }^{[28]}$. The defensive properties of tannins are generally attributed to their ability to bind proteins. Protocatechllic and chlorogenic acids probably have a special function in disease resistance of certain plants. They prevent smudge in onions, a disease caused by the fungus Colletotrichum circinans and prevent spore germination and growth of other fungi as well ${ }^{[29]}$. It is thought by some that chlorogenic acid and certain other related compounds can be readily formed and oxidised into potent fungistatic quinones by certain disease resistant cultivars but less readily so by susceptible ones.

\section{(iii) Nitrogen containing secondary metabolites}

They include alkaloids, cyanogenic glucosides, and nonprotein amino acids. Most of them are biosynthesized from common amino acids. All are of considerable interest because of their role in the anti herbivore defense and toxicity to humans.

(a) Alkaloids: A large family of $\mathrm{N}$ containing secondary metabolites found in approximately $20 \%$ of the species of vascular plants, most frequently in the herbaceous dicot and relatively a few in monocots and gymnosperms. Generally, most of them, including the pyrrolizidine alkaloids (PAs) are toxic to some degree and appear to serve primarily in defense against microbial infection and herbivoral attack. They are usually synthesized from one of the few common amino acids, in particular, aspartic acid, lysine, tyrosine and tryptophan ${ }^{[30]}$.

(b) Cyanogenic glucosides: They constitute a group of $\mathrm{N}$ containing protective compounds other than alkaloids, release the poison HCN and usually occur in members of families viz., Graminae, Rosaceae and Leguminosae ${ }^{[31]}$. They are not in themselves toxic but are readily broken down to give off volatile poisonous substances like $\mathrm{HCN}$ and $\mathrm{H} 2 \mathrm{~S}$ when the plant is crushed; their presence deters feeding by insects and other herbivores such as snails and slugs.

Amygdalin, the common cyanogenic glucoside found in the seeds of almonds, apricot, cherries and peaches while Dhurrin, found in Sorghum bicolar. Normally, both are not broken down in the intact plant because the glucosides and degradative enzymes are separated in different compartments [32]. Under ordinary conditions, this compartmentalization prevents decomposition, however, on damaging as during herbivore feeding, the cell contents of different tissues mix and form $\mathrm{HCN}$, a toxin of cellular respiration by binding to the Fe-containing heme group of cytochrome oxidase and other respiratory enzymes. Similarly, the presence of cyanogenic glucosides in cassava, make it suitable for long time storage without being attacked by pests $\left({ }^{[30]}\right.$. Lima bean (Phaseolus lunatus L.) is a model plant for studies of inducible indirect anti herbivore defences including the production of volatile organic compounds (VOCs) ${ }^{[1]}$.

(c) Non-protein amino acids: Many plants also contain unusual amino acids called non- protein amino acids that incorporated into proteins but are present as free forms and act as protective defensive substances ${ }^{[33]}$. For examples, canavanine and azetidine-2-carboxylic acid are close analogs of arginine and proline respectively. They exert their toxicity in various ways. Some block the synthesis of or uptake of protein amino acid while others can be mistakenly incorporated in to proteins. After ingestion, canavanine is recognized by herbivore enzyme that normally binds arginine to the arginine transfer RNA molecule and so become incorporated in to proteins in place of arginine. The usual result is a non-functional proteins because either its tertiary structure or it catalytic site is disrupted ${ }^{[6]}$. Plants that synthesize non-protein amino acids are not susceptible to the toxicity of these compounds but gain defense to herbivorous animals, insects and pathogenic microbes. Also, a number of plants including Arabidopsis uses Arginine as a storage and transport form of $\mathrm{N}$ and proline as a compatible solute in the defense against abiotic stresses causing water deprivation ${ }^{[34]}$.

\section{Conclusion and future prospects}

Plants have evolved multiple defense mechanisms against microbial pathogens and various types of environmental stress. Besides anti-microbial secondary metabolite, some of which are performed and some of which are induced by infection. Today, advanced tools are demanded to investigate the correct correlation between $\mathrm{N}$ and $\mathrm{S}$ fertilization and crop resistance management. In a number of previous research articles and review papers, it have shown that the $\mathrm{N}$ and $\mathrm{S}$ containing secondary metabolites are influenced by optimum supply of $\mathrm{N}$ and $\mathrm{S}$ and their good nutrition can enhance the capability of a plant to cope with biotic and abiotic stress. The identification of the mechanisms causing SIR will be an important milestone for sustainable agricultural production, as the use of fungicides could then be minimized or eliminated. Thus, SIR may become an important strategy for efficiently 
combating with pathogens in organic forming system. Therefore, additional research in area of natural pesticides development is needed in current scenario. In the long term, it will probably be possible to generate gene cassettes for complete pathways, which could then be used for production of valuable defensive secondary metabolites in bioreactors or for metabolic engineering of crop plants. This will improve their resistance against herbivores and microbial pathogens as well as various environmental stresses.

\section{References}

1. Ballhorn DJ, Kautz S, Heil M, Hegeman AD. Cyanogenesis of wild lima bean (Phaseolus lunatus L.) is an efficient direct defence in nature. Plant Signaling and Behavior. 2009; 4(8):735-745.

2. Hammond-Kosack KE, Jones JDG. Resistance gene dependent plant defence responses. Plant Cell. 1996; 8:1773-1791.

3. Schaller A, Ryan CA. Systemin- a polypeptide signal in plants. Bioessays. 1996; 18:27-33.

4. Elakovich SD. Sesquiterpenes as phytoalexins and allelopathic agents. (eds) Ecology and metabolism of plant lipids. Fuller G and Nes WD. American chemical society, Washington, D.C, 1987, 93-108.

5. Schafer H, Wink M. Medicinally important secondary metabolites in recombinant microorganisms or plants: progress in alkaloid biosynthesis. Biotechnology Journal. 2009; 4(12):1684-1703.

6. Rosenthal GA. The biochemical basis for the deleterious effects of L-canavanine. Phytochemistry. 1991; 30:10551058.

7. Rosenthal GA, Berenbaum MR. Herbivores: Their interaction with secondary plant metabolites, Ecological and evolutionary processes, 2nd edition academic press, San Diego, 1992, II.

8. Simms EL. Costs of plant resistance to herbivory. In Plant resistance to herbivores and pathogens. eds. Ecology, evolution and genetics, Fritz RS and Simms EL, Chicago: University of Chicago Press, 1992, 392-425.

9. Hartmann T. Alkaloids. In herbivores; their interaction with secondary plant metabolites, The chemical participants, 2nd ed., G.A. Rosenthal and M.R. Berenbaum, eds Academic press, San Diego. 1991; I:3385.

10. Van Etten H, Temporini E, Wasmann C. Phytoalexin (and phytoanticipin) tolerance as a virulence trait: why is it not required by all pathogens? Physiological and Molecular Plant Pathology. 2001; 59:83-93.

11. Mauricio R. Costs of resistance to natural enemies in field populations of the annual plant Arabidopsis thaliana. The American Naturalist. 1998; 151(1):20-28.

12. Gershenzon J, Croteau R. Terpenoids. In Herbivores their interaction with secondary plant metabolites, Vol I: The chemical participants, 2nd ed., G.A. Rosenthal and M.R. Berenbaum, eds, Academic press, San Diego. 1991, 165219.

13. Turlings TCJ, Loughrin JH, Mccall PJ, Roese USR, Lewis WJ, Tumlinson JH. How caterpillar-damaged plants protect themselves by attracting parasitic wasps. Proceeding of the National Academy of Sciences of the USA. 1995; 92:4169-4174.

14. Picman AK. Biological activities of sesquiterpene lactones. Biochemical systematics and Ecology. 1986; $14: 255-281$.
15. Mccarty D, Hattori T, Carson CB, Vasil V, Lazar M, Vasil IK. The vivporous-1 development gene of maize encodes a novel transcription activator. Cell. 1991; 66:895-905.

16. Irving HR, Gehring CA, Parish RW. Changes in cytosolic $\mathrm{pH}$ and calcium of guard cells precede stomatal movements. Proceedings of the National Academy of Sciences of the USA. 1992; 89:1790-1794.

17. Knoff DB. Regulatory phosphorylation of chloroplast antenna proteins, Trends Biochemical Sciences. 1991; $16: 82-83$.

18. Jagendorf AT. Acid base transition and photophosphorylation by chloroplast. Federation Proceedings. 1967; 26:1361-1369

19. Lewis WH, Elvin-Lewis MPF. Medical Botany; plants affecting mans health. Wiley, New York, 1977.

20. Mordue AJ, Blackwell A. Azadirachtin: an update. Journal of Insect Physiology. 1993; 39:903-924.

21. Eisner T, Meinwald J. Chemical ecology: The chemistry of biotic interaction. Eds, National Academy Press, Washington, DC, 1995.

22. Wuyts N, De waele D, Swennen R. Extraction and partial characterization of polyphenol oxidase from banana (Musa acuminate grandr naine) roots. Plant Physiology and Biochemistry. 2006; 44:308-314.

23. Murray RDH, Mendez J, Brown SA. The natural coumarins, Wiley, New York, 1982.

24. Serghini K, Perez De Lugue A, Castejon MM, Garcia TL, Jorrin JV. Sunflower (Helianthus annuus L.) response to broomraoe (Orobanche cernua loefl.) parasitism: induced synthesis and excretion of 7-hydroxylated simple coumarins. Journal of Experimental Botany. 2001; 52:227-234

25. Rice EL. Allelopathy, second edition. Academic Press, New York, 1984.

26. Gould JM. Probing the structure and dynamics of lignin in situ. What's New in Plant Physiology. 1983; 14:25-91.

27. Savirnata NM, Jukunen-Titto R, Oksanen E, Karjalainen RO. Leaf phenolic compounds in red clover (Trfolium pratense L.) induced by exposure to moderately elevated ozone. Environmental Pollution. 2010; 158(2):440-446.

28. Oates JF, Waterman PG, Choo GM. Food selection by the south Indian leaf-monkey, Presbytis johnii, in relation to leaf chemistry. Oecologia. 1980; 45:45-56.

29. Vickery B, Vickery ML. Secondery plant metabolism. University Park Press, Baltimore, 1981.

30. Pearce G, Strydom D, Johnson S, Ryan CA. A polypeptide from tomato leaves induces wound inducible protienase inhibitor proteins. Science. 1991; 253:895-898

31. Seigler DS. Secondary metabolites and plant systematic. Conn EE (ed), The biochemistry of plants, Vol 7. Secondery plant products. Plenum, New York and London, 1981, 139-176.

32. Poulton JE. Cyanogenesis in plants. Plant Physiology. 1990; 94:401-405.

33. Johnson R, Narvaez J, An, Ryan C. Expression of proteinase inhibitors I and II in transgenic tobacco plants: Effects on natural defence against Manduca Sexta larvae. Proceedings of the National Academy of Sciences of the USA. 1980; 86:9871-9875.

34. Funck D, Stadelhofer B, Koch W. Ornitine-deltaaminotransferase is essential for arginine catabolism but not for proline biosynthesis. BMC Plant Biology. 2009; 8:40-45. 